\title{
Assessment of difficult airway by using various bedside screening tests for endotracheal intubation
}

\author{
Sapna Bansal ${ }^{1}$, Shivani Rathee ${ }^{2 *}$, Parveen Kumar Antil ${ }^{3}$, S K Malhotra ${ }^{4}$, Inderja ${ }^{5}$ \\ ${ }^{1}$ Associate Professor, ${ }^{2}$ Senior Registrar, ${ }^{3,5}$ Postgraduate, ${ }^{4}$ Professor, Dept. of Anaesthesiology and Critical Care, Maharishi Markandeshwar \\ Institute of Medical Sciences \& Research, Mullana, Haryana, India
}

*Corresponding Author: Shivani Rathee

Email: drsapna10@gmail.com

Received: $18^{\text {th }}$ October, 2018

Accepted: $5^{\text {th }}$ February, 2019

\begin{abstract}
Introduction: The aim and objective of this study was to predict difficulty in endotracheal intubation by employing various bed side screening tests in patients posted for surgeries under general anaesthesia. Various bedside tests were used individually and in combination to assess the sensitivity and specificity in order to determine their positive predictive value and negative predictive value.

Materials and Methods: The preoperative airway assessment was conducted using multiple screening tests like interincisor gap, thyromental distance, modified mallampati test, sternomental distance and head and neck movement. Intubation was considered difficult if the view on the laryngoscopy was Cormack and lehane grade III or IV, three or more attempts at tracheal intubation, duration $>10$ min or if special maneuvers were required to facilitate intubation. The results were evaluated on the basis of sensitivity, specificity, positive and negative predictive values of these tests.

Results: The sternomental distance test has the highest sensitivity and positive predictive value of $77.3 \%$ and $63.0 \%$ and negative predictive value of $93.2 \%$ resulting as the best individual test for predicting difficulty for intubation followed by mallampati test with sensitivity of $60.0 \%$ and negative predictive value of $92.7 \%$. IIG + MMT + SMD combination resulted best with sensitivity, specificity, PPV and NPV of $98.8 \%, 26.7 \%, 88.4 \%$ and $80.0 \%$ respectively.

Conclusion: When multiple predictors were taken into consideration there was a considerable reduction in the outcome of false positives and false negatives with significant improvement in sensitivity, positive predictive value and negative predictive value. The application of multiple predictors can reduce the frequency of unanticipated difficulty and unnecessary interventions related to over- prediction of airway difficulty.
\end{abstract}

Keywords: Interincisor gap, Thyromental distance, Modified mallampati test, Sternomental distance, Head and neck movement, Difficult airway predictors.

\section{Introduction}

Maintaining the patency of the airway is the prime aim of an anaesthesiologist. Interruption of gas delivery for few minutes only can lead to dangerous events like brain hypoxia and damage or can even lead to death. The difficulty in maintaining the patency of the airway varies with individual patient's anatomical factors and therefore identification of patients with anticipated difficult airway is critical for a planned anaesthetic management to safely perform endotracheal intubation. ${ }^{1}$

The mainstay of airway management is tracheal intubation which should be usually done uneventfully. However, critical oxygen desaturation may occur if intubation is difficult or impossible after anaesthesia induction. The unexpected difficult airway is much more hazardous than a expected one. ${ }^{2}$ Unfavourable respiratory outcomes due to insufficient oxygenation, ventilation, failed intubation or accidental esophageal intubation leading to brain hypoxia, damage and death are classified as largest class of injury in American society of Anaesthesiology study. To effectively understand the risk factors associated with difficult airway will require scrutinizing protocols. ${ }^{3}$ Unplanned difficult airways are possibly due to paucity of precise predictive tests for difficult airway executed preoperatively. The only way we can prevent this is by doing a thorough assessment of the airway. ${ }^{4}$ Probability of difficult laryngoscopy using these parameters individually or in combination may help to predict difficulty during intubation. Even with the use of these parameters there have been instances when a patient predicted to have difficult intubation had an easy intubation and vice versa. ${ }^{5}$

In the present study pre-operative airway assessment of 100 patients posted for surgery under general anaesthesia was carried out to assess the efficacy of individual bedside screening tests for predicting the ease or difficulty of intubation.

\section{Aim and Objective}

1. The aim of our study was to predict difficulty in endotracheal intubation by employing various bed side screening tests.

2. To assess the sensitivity and specificity of various bed side tests in order to evaluate their positive and negative predictive value (PPV and NPV) individually and in combination.

\section{Materials and Methods}

A observational study was done in 100 ASA grade I and II patients of age group 18-45 years of either gender subjected to elective surgery planned for general anaesthesia. Patients with upper airway tumors and with abnormality of airway, cervical spine fracture and 
deformities, ASA grade III and IV, body mass index $\geq 30$ $\mathrm{kg} / \mathrm{m}^{2}$, edentulous patients, were eliminated from study.

\section{Preoperative Airway Evaluation was done with Various Bed Side Tests}

1. Inter- incisor gap (IIG) was measured by asking the patient to open the mouth fully as possible and the gap between incisors was measured. The result was graded into three levels- IIG $>5 \mathrm{~cm}$, IIG $3.5-5 \mathrm{~cm}$ and IIG-<3.5 $\mathrm{cm}$. (first two levels were taken as easy intubation and last one as difficult intubation.)

2. Thyro-mental distance (TMD) was assessed as a linear line from the mentum (chin) to the top of the thyroid notch with the neck in complete extension and the results were graded into three levels- TMD $>6.5 \mathrm{~cm}$, TMD 6.0-6.5cm, TMD $<6 \mathrm{~cm}$. (First two levels were taken as easy intubation and last one as difficult intubation.)

3. Modified Mallampati Test (MMT) was done in a seated patient with neutral head position, mouth open as wide possible with tongue protruded but without any phonation. The pharyngeal view was classified as:

Grade I: Pillars, fauces, uvula and soft palate is visualized.

Grade II: Fauces, uvula and soft palate is visualized.

Grade III: Base of uvula and soft palate is visualized.

Grade IV: Soft palate not visualized.

(Grade I and II was taken as easy intubation and III and IV as difficult intubation.)

4. Sterno-mental distance (SMD) was measured from mentum or chin to suprasternal notch with mouth closed. A sterno-mental distance of $<12.5 \mathrm{~cm}$ predicts difficult laryngoscopic intubation.

5. Head and Neck movement was assessed by using a pencil kept on patients forehead vertically in the extended position. The patient was then asked to flex the head and neck and the angle traversed by the pencil was smeasured against the horizontal. The degree of movement was grouped into three grades $>100^{\circ}$, near $90^{\circ}\left[90 \pm 10^{\circ}\right],<80^{\circ}$. (First two angles were taken as easy and third as difficult.)

A complete pre anaesthetic evaluation was done prior to the surgery along with written informed consent. Nil by mouth status was maintained. All patients were advised to take alprazolam $0.5 \mathrm{mg}$ a night before surgery and $0.25 \mathrm{mg}$ early morning along with ranitidine $150 \mathrm{mg}$ orally on the day of surgery. Preoperatively all baseline values were noted. Intravenous cannulation was done using $18 \mathrm{G}$ gauge cannula. Patients were induced with intravenous glycopyrolate, fenyanyl, propofol and vecuronium. Direct laryngoscopy was carried out with Macintosh laryngoscope blade by anaesthesiologist blinded to the study. The vocal cords were visualized and were assessed using Cormack and Lehane's (CL) Classification. Based on the parameters, difficulty in intubation was assessed. Three or more parameters predicting difficulty for laryngoscopy were taken as difficult. Endoracheal intubation was done and assessment during endotracheal intubation (easy or difficult) as well as outcome (true positive, true negative, false positive and false negative) were recorded. Maintenance of anaesthesia was done with oxygen, nitrous oxid, isoflurane and vecuronium. The patients were reversed with neostigmine and glycopyrolate administered intravenously. After extubation the patients were shifted to post-operative care unit.

\section{Statistical Analysis}

Data was analysed with software SPSS (IBM SPSS Statistics for windows, Version 21.0. Armonk, NY: IBM Corp.) Categorial data like gender, ASA grade and laryngoscopy grade were presented as numbers. Age and weight were presented as Mean \pm SD. Fisher exact test was used to calculate statistically significant difference in sensitivity and specificity of tests. $\mathrm{P}$ value of $<0.05$ was considered as significant value. Necessary sample size was estimated for a 95\% confidence interval by the use of Epi info statistical package (version 6).

\section{Results}

The patients had mean age $32.6 \pm 12.8$ years and mean weight of $64.9 \pm 12.2 \mathrm{~kg}$ in our study. Almost equal number of male and female patients participated with 46 males and 54 females. Out of 100 patients, 69 patients belonged to ASA I class and 31 patients belonged to ASA II class. During the preoperative assessment 82 patients were predicted for easy intubation and 18 patients were predicted for difficult intubation. In the study CL grading of I, II and III was seen in 55, 30 and 15 patients respectively which showed that 85 patients had easy intubation whereas 15 patients had difficult intubation. Individually SMD showed the highest sensitivity, PPV and NPV whereas IIG had the highest specificity. IIG+MMT+SMD combination resulted best with sensitivity, specificity, PPV and NPV of 98.8\%, $26.7 \%, 88.4 \%$ and $80.0 \%$, respectively. An increase in sensitivity and PPV was seen with other combinations at the cost of decline in the specificity.

\section{Discussion}

To prediction the difficult airway a rapid and reliable sereening test is required. According to Yentis et $\mathrm{al}^{6}$ the most important step while evolving a predictive test is clearly establish the end result. CL grade on laryngoscopy has been continuously used as the definition of difficult intubation as per Cormack RS et al. ${ }^{7}$ In our study a $8.3 \%$ sensitivity and $95.5 \%$ specificity of IIG showed that this test had poor ability to detect true positive patients and had PPV and NPV of $20.0 \%$ and $88.4 \%$ respectively. As per our study IIG was unable to predict difficult laryngoscopy as no correlation was found between IIG and CL grading as the pvalue was not significant. Savva et $\mathrm{al}^{8}$ and Allahyary et $\mathrm{al}^{9}$ reported similar results regarding IIG. TMD is moderately accurate to predict the difficulty grade as it had lower sensitivity as it is used for predicting difficult intubation from earlier days but its significance as a measure of difficult airway is debatable as it differs from patients to patient. Savva et $\mathrm{al}^{8}$ study showed a sensitivity of $64.7 \%$ and specificity of $81.9 \%$, positive predictive value of $15.1 \%$. 
Freck $\mathrm{CM}^{10}$ study has specificity of $81.5 \%$ while he assumed a distance of $\leq 7 \mathrm{~cm}$ as suggestive of difficult intubation.

MMT is moderately accurate to predict the difficulty grade as it had lower sensitivity and higher NPV. As per Allahyary et $\mathrm{al}^{9}$ MMT had a low sensitivity $(29.7 \%)$ and positive predictive value $(20.8 \%)$ with an acceptable specificity $(74.7 \%)$. Savva et $\mathrm{al}^{8}$ got a sensitivity of $64.7 \%$ and specificity of $66.12 \%$ which was lesser than our study. Oates et $\mathrm{al}^{11}$ in his study observed poor sensitivity with MMT which could be due to poor inter-observer variability. Karkouti et $\mathrm{al}^{12}$ also had poor inter-observer reliability with MMT and therefore poor sensitivity. Only two (mouth opening and chin protrusion) out of ten tests showed excellent inter-observer reliability. The $77.3 \%$ sensitivity and $87.2 \%$ specificity of SMD showed that this test had the best ability to detect true positive patients as this test had the highest sensitivity and PPV, $63.0 \%$. This test also had NPV of $93.2 \%$ which denotes that this test has ability to detect true negative also. Savva et $\mathrm{al}^{8}$ found $82.4 \%$ sensitivity and $88.6 \%$ specificity of SMD. Allahyary et $\mathrm{al}^{9}$ study showed high specificity of $86.7 \%$.

Atlanto-occipital joint extension is also a tool for assessing the difficult airway. As per Gupta $S$ et $\mathrm{al}^{13}$ assessment of atlanto-occipital joint is necessary to make proper position for intubation which aligns all the three axis. Kuriakose $\mathrm{R}$ et al ${ }^{14}$ showed AOJE had a poor sensitivity of $2.5 \%$, but $100 \%$ specificity and PPV. Both IIG and AOJE predicted easy intubation better. Bhatnagar $\mathrm{S}$ et $\mathrm{al}^{15}$ study showed subjective neck movement assessment had $31 \%$ sensitivity, $97 \%$ specificity and $77 \%$ positive predictive value.

Combination of all five tests increased the sensitivity and NPV to $100 \%$ while PPV was also increased to $88.4 \%$ but decreased the specificity to $6.7 \%$. IIG+MMT+SMD combination resulted best with sensitivity, specificity, PPV and NPV of $98.8 \%, 26.7 \%, 88.4 \%$ and $80.0 \%$ respectively. An increase in sensitivity and PPV was seen with other combinations at the cost of lowering the specificity. In the study by Allahyary et $\mathrm{al}^{10}$ the combination of tests improved the sensitivity, specificity, PPV and NPV to $97 \%, 100 \%$, $100 \%$ and $86 \%$, respectively.

Table 1: Patient characteristics

\begin{tabular}{|l|c|}
\hline & Mean \pm SD \\
\hline Age & $32.6 \pm 12.8$ \\
\hline Gender (M/F) & $46 / 52$ \\
\hline Weight (Kg) & $64.9 \pm 12.2$ \\
\hline ASA grade (I/II) & $69 / 31$ \\
\hline
\end{tabular}

Table 2: Preoperative assessment (POA) distribution

\begin{tabular}{|l|c|c|}
\hline \multicolumn{1}{|c|}{ POA } & $\begin{array}{c}\text { Number of } \\
\text { patients }\end{array}$ & Percentage (\%) \\
\hline Easy & 82 & 82.0 \\
\hline Difficult & 18 & 18.0 \\
\hline Total & 100 & 100.0 \\
\hline
\end{tabular}

Table 3: Cormack and lehane grading distribution

\begin{tabular}{|l|c|c|}
\hline Grade & No. of patients & Percentage (\%) \\
\hline I & 55 & 55.0 \\
\hline II & 30 & 30.0 \\
\hline III & 15 & 15.0 \\
\hline IV & 0 & 0.0 \\
\hline Total & 100 & 100.0 \\
\hline
\end{tabular}

Table 4: Outcome distribution

\begin{tabular}{|l|c|c|}
\hline Outcome & No. of patients & $\begin{array}{c}\text { Percentage } \\
(\mathbf{\%})\end{array}$ \\
\hline False Negative & 6 & 6.0 \\
\hline False Positive & 9 & 9.0 \\
\hline True Negative & 76 & 76.0 \\
\hline True Positive & 9 & 9.0 \\
\hline Total & 100 & 100.0 \\
\hline
\end{tabular}

Table 5: Assessment of all the tests during laryngoscopy

\begin{tabular}{|l|c|c|c|c|}
\hline Group & Sensitivity & Specificity & PPV & NPV \\
\hline IIG & $8.3 \%$ & $95.5 \%$ & $20.0 \%$ & $88.4 \%$ \\
\hline TMD & $35.3 \%$ & $95.2 \%$ & $60.0 \%$ & $87.8 \%$ \\
\hline MMT & $60.0 \%$ & $89.4 \%$ & $50.0 \%$ & $92.7 \%$ \\
\hline SMD & $77.3 \%$ & $87.2 \%$ & $63 \%$ & $93.2 \%$ \\
\hline HNM & $21.4 \%$ & 95.4 & $42.9 \%$ & $88.2 \%$ \\
\hline
\end{tabular}

Table 6: Comparison of all the five tests with overall difficult intubation

\begin{tabular}{|l|c|c|c|c|}
\hline \multicolumn{1}{|c|}{ Comparisons } & Sensitivity & Specificity & PPV & NPV \\
\hline IIG + TMD & 100.0 & 6.7 & 85.9 & 100.0 \\
\hline IIG + MMT & 98.8 & 26.7 & 88.4 & 80.0 \\
\hline IIG + SMD & 98.8 & 26.7 & 88.4 & 80.0 \\
\hline IIG + HNM & 100.0 & 13.3 & 86.7 & 80.0 \\
\hline IIG + TMD+MMT & 100.0 & 6.7 & 85.9 & 100.0 \\
\hline IIG + TMD + SMD & 100.0 & 6.7 & 85.9 & 100.0 \\
\hline IIG+MMT+SMD & 98.8 & 26.7 & 88.4 & 80.0 \\
\hline IIG + MMT + HNM & 100.0 & 13.3 & 86.7 & 100.0 \\
\hline IIG + SMD + HNM & 100.0 & 13.3 & 86.7 & 100.0 \\
\hline $\begin{array}{l}\text { IIG + TMD + MMT } \\
\text { + SMD }\end{array}$ & 100.0 & 6.7 & 85.9 & 100.0 \\
\hline
\end{tabular}

\section{Conclusion}

The conclusion of the study is that when multiple predictors were taken into consideration there was a considerable reduction in the outcome of false positives and false negatives with significant improvement in sensitivity, positive PPV and NPV. The application of multiple predictors can predict difficult airway more effectively thereby reducing the indicence of unpredicted difficult airway.

\section{Conflict of Interest: None.}

\section{References}

1. El-Ganzouri AR, McCarthy RJ, Tuman KJ, Tanck EN, Ivankovich AD. Preoperative airway assessment: Predictive value of a multivariate risk index. Anesth Analg 1996;82:1197204. 
2. Adamus M, Jor O, Vavreckova T, Hrabalek L, Zapletalova J, Gabrhelik T et al. Inter-observer reproductibility of 15 tests used for predicting difficult intubation. Biomed Pao Med Fac Univ Palacky Olomouc Czech Repub 2011;155:275-82.

3. Caplan RA, Posner KL, Ward RJ, Cheney FW. Adverse respiratory events in anesthesia: a closed claim analysis. Anesthesiol 1990;72:828-33.

4. Finucane BT. Principles of airway management, 4 th edition. Springer. 2011:27-58.

5. Arne J, Descoins P, Fusciardi J, Ingrand P, Ferrier B, Boudigues $\mathrm{D}$ et al. Preoperative assessment for difficult intubation in general and ENT surgery: predictive value of a clinical multivariate risk index. Br J Anaesth 1998;80:140-6.

6. Yentis SM. Predicting difficult intubation - worthwhile exercise or pointless ritual? Anaesth 2002;57:105-9.

7. Cormack RS, Lehane J. Difficult tracheal intubation in obstetrics. Anaesth 1984;39:1105-11.

8. Savva D. Prediction of difficult tracheal intubation. Br J Anesth 1994;73:149-53.

9. Allahyary E, Ghaemei SR, Azemati S. Comparison of six methods for predicting difficult intubation in obstetric patients. IRCMJ 2008;10:197-204.

10. Frerk CM. Predicting difficult intubation. Anesth 1991;46:1005-8.

11. Oates JDL, Macleod AD, Oates PD, Pearsall FJ, Howie JC, Murray GD. Comparison of two methods for predicting difficult intubation. Br J Anaesth 1991;66:305-9.
12. Karkouti K, Rose DK, Ferris LE, Wigglesworth DF, Fard TM, Lee H. Inter-observer reliability of ten tests used for predicting difficult tracheal intubation. Can J Anaesth 1996;43:554-9.

13. Gupta S, Sharma R, Jain D. Airway assessment: Prediction of difficult airway. Indian J Anaesth 2005;49:257-62.

14. Kuriakose R, Mathew A, Koshy RC. Screening tests for predicting difficult endotracheal intubation a clinical assessment in facio-oro-maxillary and neck malignancy patients. J Anaesth 2003;19:37-44.

15. Bhatnagar S, Mishra S, Jha RR, Singhal AK. Predicting difficult laryngoscopy in oral cancer patients: A Prospective Study. Indian J Anaesth 2005;49:413-6.

How to cite this article: Bansal S, Rathee S, Antil PK, Malhotra SK, Inderja. Assessment of difficult airway by using various bedside screening tests for endotracheal intubation. Indian J Clin Anaesth 2019;6(2):270-3. 